23446

Organic Analytical Reagents

By Pruf. Frank J. Welener. Vol. 3. Pp. xi+593. Vol. 4. Pp. xiii +624. (New York: D. Van Nostrand Co., Inc. ; London : Macmillan and Co., Ltd., 1947.) 44s. net each.

T $\mathrm{T}$ would appear that these two volumes complete Ihe author's survey of organic substances used in analysis. Volume 3 de 10 with heterocyclic nitrogen compounds, ox An sutrid acidic imino compounds, and volume 4 ith number of groups of compounds, including natoids, other natural substances and valoy llasses of dyes. Among the more important seltions in volume 3 are extensive reviews of the uses of dimethylglyoxime (60 pages), cupferron (41 pages), and dithizone (83 pages), with detailed discussions of the conditions for their use and the factors determining the stability of the complexes formed with metals. The bibliographies in these three sections alone contain some 670 references to the literature.

The usefulness of these volumes as a work of reference would be much increased by the addition of combined indexes covering all four volumes. The analyst who uses them to find what reagents are suitable for the detection or determination of a given metal will otherwise have to search four indexes in every case. The general arrangement of the organic substances is also in some respects arbitrary; for example, the reagent 8-hydroxyquinoline is found in volume 1 under phenols and not in volume 3 under heterocyclic nitrogen compounds, so that in the absence of a combined index the search for a given organic reagent will also often involve the perusal of more than one list. However, this is a minor point, and there can be no doubt that these volumes are the key to an enormous amount of detailed information and will be of great value to the practical worker.

G. M. B.

\section{The Birds of Tropical West Africa}

With Special Reference to those of the Gambia, Sierra Leone, the Gold Coast and Nigeria. By Dr. David Armitage Bannerman. Vol. 6. Pp. xxxix+ 364+14 plates. (London: Crown Agents for the Colonies, 1948.) 35s.

$\triangle$ FTER a gap of eight feathoue to the War and its after-effects, pulfitation of this important work is resumed titbrif $\theta$ appearance of the sixth volume; and of (s glad to note that the remaining two volymas soready for press. The present volume coprs Pun families of the Passeriformes; the sevprth will deal with the weaver-birds; and the eignth will contain additional information that has meanwhile come to hand on the subjects of the first five volumes. This last will certainly be an essential part of the work, as the first volume appeared so long ago as 1930, and something of the kind would have been necessary even if the period of issue had not been prolonged by the War.

The whole work gives a systematic account of all the species of birds known to occur in the Gambia, Sierra Leone, the Gold Coast and Nigeria. For each species there is given a description, with notes on field identification, and an account of what is known of its range and local distribution and of its habits. Such comprehensive documentation for the avifauna of tropical territories is quite unusual, and the Governments of the four Colonies have done well to sponsor the undertaking. The work will provide an invaluable base-line and guide for all further ornitho-
February 12, 1949 Vol. 163

logical studies in the area, about the birds of which there is naturally still a great deal to be discovered. In congratulating the author on the approaching completion of his task, one is also glad to note that the standard of production has been well maintained in this post-war volume.

The Petrography and Petrology of South African Clays

By V. L. Bosazza. Pp. $x v+313+18$ plates. (Johannesburg: The Author, 39 Barkly Road, Parktown; London: Percy Lund, Humphries and Co., Ltd., n.d.) $42 s$.

THIS volum 0 se a useful purpose by bringing togethemplariety of chemical, physical and peyrolog foll data which have been obtained by the aut $\mathrm{pr}$ and others over a period of years. It deserves tof be referred to frequently, and one must regret, therefore, that the arrangement of the text makes reference difficult. The numerous analyses are quoted mainly as illustrations in the development of a general thesis on the nature of clay, and consequently data on the same or neighbouring clay deposits are often widely scattered. The index is not sufficiently complete to repair this fault.

The term 'clay' is interpreted in a wide sense, and analytical data are given on soils, siliceous deposits, iron-alumina hydrates and tillite, as well as on such materials as fireclays and kaolins. There is an almost complete absence of data obtained by modern physical techniques (X-ray diffraction, electron microscopy, differential thermal analysis), and the author's reference to the X-ray method (p. 167) suggests that he does not appreciate its present possibilities.

The book is very legibly reproduced from typescript by the 'Replika' process, but readability is impaired by numerous errors in the original typescript. The voluminous list of general references indicates a thorough acquaintance with the literature of clay mineralogy, and most readers should find in it something new to them. Douglas M. C. MacEwan

\section{Mereside Chronicle}

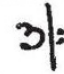

With a Short Interlude of Lochs and Lochans. By C. F. Tunnicliffe. Pp. 200. (London: Country Life, Ltd.; New York: Charles Scribner's Sons, 1948.) 42s. net.

NR. Tunnicliff 4 "tteside Chronicle" is an 1 accont 90 peaceful waters in lovely country settings, Fibere birds of many kinds disport themselves yntisturbed.

A khown to the ornithological world but also to a wider public. He is skilled in depicting feathered life, having that delicacy of touch which is necessary for the successful portrayal of birds.

The illustrations to this handsome volume are many; that used on the jacket, of Canada geese and goslings, being particularly satisfying, for one reason because the black, white and grey subject is especially suitable for reproduction in monochrome.

It is a pity that some of the lovely subjects could not be reproduced in full colour, for the artist we know is as much master of the brush as he is of pencil and pen.

By the way, Mr. Tunnicliffe does not confine himself to English subjects, and his sketches of divers in the Highlands are full of life, as also are other pictures of Scottish birds. 